Loyalitas Kreativitas
Aldi Masyarakat Kreatif

P-ISSN 2722-2101, E-ISSN 2722-4201

Program Studi Ekonomi Manajemen Universitas Pamulang

Jurnal LOKABMAS Kreatif Vol.02,No.01,Maret 2021 Hal.71-76

Email:jurnalkreatif.manajemen@gmail.com

\title{
PELATIHAN PEMBUKUAN DAN PENCATATAN KEUANGAN SEDERHANA MENUJU ENTERPRENEUR MUDA YANG KREATIF DAN INNOVATIF KEPADA KARANG TARUNA RW 11 KELURAHAN PENGASINAN, KECAMATAN SAWANGAN, KOTA DEPOK
}

\author{
Kemas Vivi Andayani, Herry Suherman, \\ Ryan Elfahmi, Hadyati Harras, Agus
}

Dosen Ekonomi Fakultas Ekonomi Universitas Pamulang

Email dosen01342@unpam.ac.id, dosen01060@unpam.ac.id, dosen01363@unpam.ac.id, dosen01016@unpam.ac.id, dosen01365@unpam.ac.id

\section{ABSTRAK}

Tujuan dari Kegiatan Pengabdian Kepada Masyarakat adalah untuk melaksanakan salah satu Tri Dharma Perguruan Tinggi. Selain itu diharapkan dapat memberikan pemahaman bagi anggota keluarga tentang pencatatan dan pembukuan transaksi keuangan agar dapat mempermudah suatu keluarga dalam mengelola keuangan keluarga sehingga dapat direncanakan dengan sebaikbaiknya, atau dalam lingkup lebih luas untuk mengkalkulasi, mengkontrol serta mengatur keseluruhan transaksi keuangan yang terjadi sepanjang keberlangsungan dunia usaha.

Metode pelaksanaan pengabdian ini dilakukan secara sistematis dan terbagi dalam beberapa kegiatan mulai dari tahap survei berupa sosialisasi yang dilakukan dengan menyusun program-program yang akan disampaikan saat kegiatan pengabdian masyarakat dilangsungkan, meliputi: penyusunan materi dan jadwal serta pembagian tugas tim pengabdian serta survei lokasi pengabdian. Tahap sosialisasi yaitu berupa silaturahmi dengan Ketua dan pengurus Karang Taruna RW 11 Kelurahan Pengasinan Kecamatan Sawangan Depok dan menyampaikan maksud dan tujuan pengabdian serta hasil yang diharapkan. Pada tahap ini juga dilakukan perjanjian kerjasama pengabdian serta menentukan jadwal acara berlangsung. Tim pelaksana kegiatan pengabdian pada masyarakat adalah dosen Fakultas Ekonomi program studi Manajemen S1 beranggotakan 5 orang. Tim pengabdian akan memberikan materi tentang pencatatan dan pembukuan keuangan sederhana menuju entrepreneur muda yang kreatif dan inovatif, dilanjutkan dengan pemberian pelatihan melalui media video konferensi oleh dosen UNPAM.

Hasil pengabdian masyarakat yang diperoleh adalah bertambahnya keilmuan bagi Para Peserta mengenai bagaimana cara mencatat dan melakukan pembukuan keuangan baik untuk keuangan keluarga maupun keuangan usaha. Harapan kami dengan pengabdian ini dapat memberikan bantuan untuk meningkatkan kemampuan peserta secara langsung dan tepat sasaran, serta membuka wawasan masyarakat khususnya generasi muda entrepreneur tentang pembukuan sebagai dasar untuk mengukur kinerja keuangan suatu bisnis dan dengan ilmu yang diperoleh pada kegiatan ini diharapkan mampu memberikan semangat baru bagi para dosen dan tenaga pengajar sebagai kontributor yang memotivasi khususnya bagi generasi muda entrepreneur.

\section{Kata Kunci: Pencatatan Keuangan, Pembukuan Sederhana, Entrepreneur}




\section{Loyalitas Kreativitas \\ Aldi Masyarakat Kreatif}

P-ISSN 2722-2101, E-ISSN 2722-4201

Program Studi Ekonomi Manajemen Universitas Pamulang

Jurnal LOKABMAS Kreatif Vol.02,No.01,Maret 2021 Hal.71-76

Email:jurnalkreatif.manajemen@gmail.com

\begin{abstract}
ABSTRAC
The purpose of Community Service Activities is to carry out one of the Tri Dharma of Higher Education. In addition, it is hoped that it can provide understanding for family members about the recording and bookkeeping of financial transactions in order to make it easier for a family to manage family finances so that it can be planned as well as possible, or in a broader scope to calculate, control and regulate all financial transactions that occur throughout its business world life.

This method of implementing this service is carried out systematically and is divided into several activities starting from the survey stage in the form of socialization which is carried out by compiling programs that will be delivered when community service activities are carried out, including: preparation of materials and schedules as well as division of tasks for the service team and survey of service locations. The socialization stage is in the form of friendship with the chairman and management of the Youth Organization RW 11, Pengasinan Village, Sawangan Depok District and conveying the aims and objectives of the service and the expected results. At this stage, a community service cooperation agreement is also made and determines the schedule for the event to take place. The team for implementing community service activities is a 5-member lecturer at the Faculty of Economics, S1 Management study program. The community service team will provide material on simple financial recording and bookkeeping towards creative and innovative young entrepreneurs, followed by providing training through video conference media by UNPAM lecturers.

The result of community service that was obtained was the increase in knowledge for the Participants on how to record and do financial bookkeeping for both family finances and business finances. We hope that this dedication can provide assistance to improve the ability of participants directly and on target, as well as open people's insights, especially the younger generation of entrepreneurs, about bookkeeping as a basis for measuring the financial performance of a business and with the knowledge gained in this activity it is hoped that it will be able to provide new enthusiasm for lecturers and teaching staff as motivating contributors, especially for the younger generation of entrepreneurs.
\end{abstract}

\title{
Keywords: Financial Records, Simple Bookkeeping, Entrepreneurs
}

\section{PENDAHULUAN}

Data Badan Pusat Statistik menunjukan jumlah pelaku UMKM mencapai 99\% dari sejumlah karang taruna di Indonesia, nilai investasi UMKM mencapai 52,9\% dari total investasi. Oleh karenanya dibutuhkan pencatatan dan pembukuan yang baik untuk usaha UMKM terlebih lagi pada usia muda. Pembukuan adalah suatu proses pencatatan yang dilakukan secara teratur untuk mengumpulkan data dan informasi keuangan yang meliputi harta, kewajiban, modal, penghasilan, dan biaya, serta jumlah harga perolehan dan penyerahan barang atau jasa, yang ditutup dengan menyusun laporan keuangan berupa neraca, dan laporan laba rugi untuk periode tahun pajak tersebut. Sedangkan pencatatan adalah pengumpulan data yang dikumpulkan secara teratur tentang peredaran atau penerimaan bruto dan/atau penghasilan bruto sebagai dasar untuk menghitung jumlah pajak yang terutang.

Karang Taruna Rw 11 Kelurahan Pengasinan, Provinsi Jawa Barat, Kota Depok yang sebagian besar adalah generasi muda selalu aktif dalam melakukan kegiatan bisnis untuk membantu pemahaman mereka dalam kegiatan sehari-hari. Kegiatan yang mereka lakukan erat kaitannya dengan kegiatan bisnis, oleh karenannya diperlukan penambahan ilmu tentang pembukuan dan pencatatan untuk mendukung kegiatan bisnis atau usaha mereka, dimana apabila sejak dini sudah diajarkan kelak usaha UMKM yang mereka rintis dapat berhasil dan maju.

Pencatatan dan Pembukuan Pencatatan adalah setiap transaksi dari suatu kegiatan usaha merupakan suatu informasi awal yang harus dicatat dan diolah, sehingga 


\section{Loyalitas Kreativitas \\ Aldi Masyarakat Kreatif}

P-ISSN 2722-2101, E-ISSN 2722-4201

Program Studi Ekonomi Manajemen Universitas Pamulang

Jurnal LOKABMAS Kreatif Vol.02,No.01,Maret 2021 Hal.71-76

Email:jurnalkreatif.manajemen@gmail.com terbentuk sebuah laporan keuangan. Pembukuan adalah suatu proses pencatatan yang dilakukan secara teratur untuk mengumpulkan data dan informasi keuangan yang meliputi harta, kewajiban, modal, penghasilan dan biaya, serta harga perolehan dan penyerahan barang atau jasa, yang ditutup dengan menyusun laporan keuangan berupa neraca, dan laporan laba rugi untuk periode Tahun Pajak tersebut.

Tujuan dari Pencatatan dan Pembukuan Sederhana Agar dapat mempermudah suatu keluarga dalam mengelola keuangan keluarga sehingga dapat direncanakan dengan sebaik-baiknya. Selain itu untuk mengkalkulasi, mengkontrol serta mengatur keseluruhan transaksi keuangan yang terjadi sepanjang keberlangsungan dunia usahanya.

Pengertian aset, liabilities, dan equity Aset adalahsumber ekonomi yang diharapkan memberikan manfaat usaha di kemudian hari Liabilities (hutang) Kewajiban suatu badan usaha / perusahaan kepada pihak ketiga yang dibayar dengan cara menyerahkan aktiva atau jasa dalam jangka waktu tertentu sebagai akibat dari transaksi di masa lalu. Equity sesuatu yang digunakan untuk mendirikan atau menjalankan suatu usaha.

\section{RUMUSAN MASALAH}

1. Pentingnya Karang Taruna bagi entrepreneur muda yang ada dilingkungan RW 11 Kelurahan Pengasinan memahami proses pembukuan.

2. Pentingnya Karang Taruna bagi entrepreneur muda yang ada dilingkungan RW 11 Kelurahan Pengasinan memahami proses pencatatan transaksi.

3. Pentingnya Karang Taruna bagi entrepreneur muda mengetahui apakah bisnis anda menguntungkan atau justru merugikan

4. Pentingnya Karang Taruna bagi entrepreneur muda membuat laporan keuangan yang diperlukan untuk memperoleh pendanaan dari pihak ketiga, misalnya dari Bank

5. Pentingnya Karang Taruna bagi entrepreneur muda melakukan pencatatan keuangan usaha harus dipisahkan dengan keuangan pribadi

\section{TUJUAN PELAKSANAAN}

Dalam Tri Darma Perguruan Tinggi ada tiga kewajiban yang harus dijalankan oleh Perguruan Tinggi dalam mengelolah seluruh komponen yang ada didalamnya (civitas akademika), yaitu dharma pendidikan pengajaran, dharma penelitian dan dharma pengabdian masyarakat.

Pengabdian kepada masyarakat pada hakikatnya membantu masyarakat agar masyarakat mau dan mampu memenuhi kebutuhannya sendiri. Dengan demikian azas pengabdian kepada masyarakat sesuai dengan azas kemanusia yang menenkankan pada usaha pengembangan masyarakat sebagai subyek pembangunan. Kemudian pengabdian kepada masyarakat harus dilandasi pada kepercayaan dan kemampuan serta kekuatan masyarakat itu sendiri. Pengabdian kepada masyarakat yang dilakukan oleh dosen sebagai salah satu dharma atau tugas pokok perguruan tinggi. Dengan dilaksanakannya Tri Dharma Perguruan Tinggi kepada masyarakat dalam bentuk pelatihan, dan lainlain, diharapkan ada keterkaitan bahkan kebersamaan antara perguruan tinggi dan masyarakat. Hal ini dapat diartikan sebagai pengamalan IPTEK melalui metode ilmiah langsung kepada masyarakat yang butuh, dalam upaya mensukseskan pembangunan, mengembangkan manusia ke dalam sektor pembangunan dan meningkatkan taraf kehidupan masyarakat.

\section{TINJAUAN PUSTAKA}

\section{Enterpreneur Perlu Tahu}

Data Badan Pusat Statistik menunjukan jumlah pelaku UMKM mencapai 99\% dari sejumlah karang taruna di Indonesia,

nilai investasi UMKM mencapai 52,9\% dari total investasi. Oleh karenanya dibutuhkan 
pencatatan

dan pembukuan yang baik untuk usaha UMKM terlebih lagi pada usia muda. Pembukuan adalah suatu proses pencatatan yang dilakukan secara teratur untuk mengumpulkan data dan informasi keuangan yang meliputi harta, kewajiban, modal, penghasilan, dan biaya, serta jumlah harga perolehan dan penyerahan barang atau jasa, yang ditutup dengan menyusun laporan keuangan berupa neraca, dan laporan laba rugi untuk periode tahun pajak tersebut. Sedangkan pencatatan adalah pengumpulan data yang dikumpulkan secara teratur tentang peredaran atau penerimaan bruto dan/atau penghasilan bruto sebagai dasar untuk menghitung jumlah pajak yang terutang.

$$
\text { Pencatatan dan Pembukuan }
$$

Pencatatan adalah setiap transaksi dari suatu kegiatan usaha merupakan suatu informasi awal yang harus dicatat dan diolah, sehingga terbentuk sebuah laporan keuangan. Pembukuan adalah suatu proses pencatatan yang dilakukan secara teratur untuk mengumpulkan data dan informasi keuangan yang meliputi harta, kewajiban, modal, penghasilan dan biaya, serta harga perolehan dan penyerahan barang atau jasa, yang ditutup dengan menyusun laporan keuangan berupa neraca, dan laporan laba rugi untuk periode Tahun Pajak tersebut.

Menurut Pasal 1 angka 26 UU KUP 2.2 Pendukung Pencatatan dan Pembukuan Sederhana 1) Faktur Faktur adalah bukti penjualan barang yang dilakukan secara kredit yang dibuat oleh pihak penjual dan diberikan kepada pihak pembeli. 2) Kwitansi merupakan bukti transaksi bahwa yang bersangkutan telah menerima uang atau telah membayar uang secara tunai. 3) Nota Kredit Bukti transaksi penerimaan kembali barang yang telah dijual secara kredit (retur penjualan), atau pengurangan harga faktur karena barang sebagian rusak atau kualitas yang tidak sesuai dengan pesanan. Dalam hal demikian nota kredit dibuat oleh pihak penjual dan dikirimkan kepada pihak pembeli. 4) Nota Debit Bukti transaksi pengiriman kembali barang yang dibeli karena sebagian barang yang dibeli ada yang rusak atau tidak sesuai pesanan. Maka, nota debet dibuat oleh pembeli untuk dikirimkan kepada penjual.

Tujuan dari Pencatatan dan Pembukuan Sederhana Agar dapat mempermudah suatu keluarga dalam mengelola keuangan keluarga sehingga dapat direncanakan dengan sebaik-baiknya. Selain itu untuk mengkalkulasi, mengkontrol serta mengatur keseluruhan transaksi keuangan yang terjadi sepanjang keberlangsungan dunia usahanya.

Pengertian aset, liabilities, dan equity Aset adalahsumber ekonomi yang diharapkan memberikan manfaat usaha di kemudian hari Liabilities (hutang) Kewajiban suatu badan usaha / perusahaan kepada pihak ketiga yang dibayar dengan cara menyerahkan aktiva atau jasa dalam jangka waktu tertentu sebagai akibat dari transaksi di masa lalu. Equity sesuatu yang digunakan untuk mendirikan atau menjalankan suatu usaha.

\section{Manfaat Bagi Masyarakat}

Pembukuan merupakan hal yang penting dan menjadi salah satu penunjang keberhasilan sebuah perusahaan. Menurut UU Nomor 28 Tahun 2007 Pasal 28, beberapa hal yang dicatat dalam pembukuan berupa data dan informasi keuangan yang meliputi harta, kewajiban, modal, penghasilan, biaya, serta jumlah harga perolehan dan penyerahan barang atau jasa, yang ditutup dengan menyusun laporan keuangan berupa neraca dan laporan laba rugi untuk periode tahun pajak tersebut. Item yang cukup banyak ini membuat anggapan bahwa pembukuan hanya diperlukan oleh perusahaan besar saja. Padahal bisnis kecil juga sangat membutuhkannya karena banyak manfaat pembukuan yang bisa didapat oleh bisnisbisnis ini.

Meskipun transaksi yang dilakukan masih sedikit, manfaat pembukuan dapat dirasakan pada bisnis baru dan kecil yang kerap masih bingung dan luput dalam pengalokasian modal serta dana. Oleh karena itu, permasalahan yang terjadi saat ini banyak bisnis kecil yang gulung tikar karena belum menyadari manfaat pembukuan 
sehingga tidak konsisten dalam pencatatan atau bahkan tidak melakukannya.

Banyak alasan mengapa banyak pemilik bisnis kecil tidak melakukan pembukuan pada bisnisnya. Pertama, karena mereka merasa proses pembukuan ini cukup merepotkan dan kurang mengerti dalam melakukannya sehingga malas melakukannya. Kedua, karena tidak mengerti sehingga ini yang membuat pemilik bisnis merasa harus mengeluarkan biaya lebih untuk menyewa seorang akuntan. Ketiga, pemilik bisnis kerap mengeluhkan keterbatasan waktu yang dimiliki untuk melakukan pembukuan. Untuk hal ini, pemilik bisnis bisa menyicil dengan membuat catatan kecil setiap sebuah transaksi sudah selesai. Setelah itu, catatan kecil ini tinggal dirapikan setelah jam operasional bisnis dan dimasukkan dalam buku besar.

Ketika sudah bertekad untuk mendirikan sebuah bisnis, maka dibutuhkan usaha yang optimal untuk mengembangkannya. Salah satunya yaitu dengan melakukan pembukuan sederhana yang dilakukan secara rutin. Berikut beberapa manfaat yang bisa didapatkan oleh pemilik bisnis ketika melakukan pembukuan secara rutin.

Memberikan pelatihan kepada Karang Taruna Rw 11 Kelurahan Pengasinan, Provinsi Jawa Barat, Kota Depok agar mendapatkan pemahaman dan penjelasan beberapa masalah yang berkaitan dengan bisnis yang akan dijalankan. Diantaranya adalah: 1) Meminimalisasi Kelebihan Pengeluaran. 2) Mengetahui Untung atau Tidaknya Sebuah Bisnis. 3) Membantu Strategi Bisnis Selanjutnya. 4) Memudahkan Pelaporan Pajak. 5) Memberikan Gambaran Jelas Bagi Kreditur dan Investor.

\section{HASIL DAN PEMBAHASAN}

Antusias karang taruna dalam melihat kesempatan menerima pengetahuan ini cukup baik. Tim Pelaksana telah melaksanakan kegiatan pelatihan penyusunan laporan keuangan dengan teknik pembukuan sederhana: Tahap Persiapan Pelatihan Dari hasil survey dan wawancara serta koordinasi dengan mitra di lapangan, Tim Pelaksana memperhatikan dalam menyiapkan materi yang akan diberikan dalam kegiatan pelatihan. Selain menyiapkan materi, Tim Pelaksana juga berkoordinasi dengan para mitra untuk mempermudah pelaksanaan pelatihan. Adapun materi yang diberikan, antara lain: a) Pentingnya Kewirausahaan bagi Karang taruna, b) Pentingnya Manajemen Keuangan bagi Karang taruna, c) Teknik Pembukuan Sederhana dalam menyusun laporan keuangan usaha, serta d) cara mengukur produkvitias usaha mitra maupun para peserta pelatihan.

Peserta memiliki daya tanggap terhadap materi yang diberikan oleh pemateri. Dalam kegiatan pelatihan peserta mampu berinteraksi secara aktif dalam mempresentasikan hasil pelatihan. Pada akhir kegiatan peserta dievaluasi untuk mengetahui sejauhmana peserta menyerap ilmu ataupun materi yang disajikan.

\section{KESIMPULAN DAN SARAN Kesimpulan}

Melalui program pemberdayaan ini dapat disimpulkan peserta :

1. Memahami akuntansi keuangan

2. Memahami prinsip dasar dan tujuan akuntansi keuangan

3. Mampu menyusun laporan keuangan neraca, laba-rugi dan laporan perubahan modal dan melakukan analisis rasio terkait

4. Memahami dan mampu mempraktekan prosedur dalam siklus akuntansi

5. Memahami berbagai metode akuntansi yang berkaitan dengan piutang ragu-ragu dan persediaan

\section{Saran}

Dari pelaksanaan kegiatan pengabdian kepada masyarakat tersebut masih ditemukan berbagai kendala yang perlu disempurnakan, oleh karena itu perlu diberikan saran Karang Taruna berikut ini: 
Loyalitas Kreativitas

Aldi Masyarakat Kreatif
P-ISSN 2722-2101, E-ISSN 2722-4201

Program Studi Ekonomi Manajemen Universitas Pamulang Jurnal LOKABMAS Kreatif Vol.02,No.01,Maret 2021 Hal.71-76

Email:jurnalkreatif.manajemen@gmail.com
Mempelajari secara intensif pola penyusunan laporan keuangan

2. Keuangan usaha harus terpisah dari keuangan pribadi

3. Objektivitas pencatatan transaksi harus berdasarkan sumber/dokumen yang nyata seperti faktur, kuitansi/nota dan tagihan dari pemasok

4. Kegiatan yang dicatat diukur dengan uang. Rapi dan mudah dalam penyajian jika diperlukan

\section{DAFTAR PUSTAKA}

Handayani, Annisa Yulia. Persepsi Pemuda terhadap Peranan Karang Taruna dalam Penanganan Masalah Sosial.2015. Jurnal penyuluhan Vol.11 No.1

Bank Indonesia. (2015). Profil Bisnis UMKM.Penerbit Bank Indonesia kerjasama dengan Lembaga Pengembangan Perbankan Indonesia. Jakarta.

Harahap, S.S.(2002). Teori Akuntansi Laporan Keuangan. Bumi Aksara. Jakarta.

Oktrima, B., Virby, S., \& Fauziah, G. (2020). PENTINGNYA MANAJEMEN KEUANGAN KELUARGA PADA IBU PKK KELURAHAN PONDOK BENDA GUNA MEMINIMALISIR PENGELUARAN DAN ANIMO MENABUNG DITENGAH PANDEMI COVID-19. JURNAL LOKABMAS KREATIF, 1(3), 112-123.

Peraturan Menteri Sosial Republik Indonesia. (2010). Pedoman Dasar Karang Taruna. Kementerian Sosial Republik Indonessia, 21 September 2010.

SMERU. (2003). Upaya Peningkatan Usaha Mikro dalam Rangka Peningkatan Ekonomi Perempuan (Sukabumi, Bantul, Kebumen, Padang, Surabaya dan Makassar).Kerjasama Lembaga Penelitian SMERU dan Kementerian Pemberdayaan Perempuan. Jakarta.
Sukirno, S. (2013). Pengantar Ekonomi Makro.Penerbit PT. RajaGrafindo Persada. Jakarta

Virby, S., Palupi, P., Japanis, R., \& Rodiyana, N. (2020). PENTINGNYA MENGELOLA KEUANGAN SEJAK USIA DINI SISWA SISWI (TAMAN KANAK-KANAK) UNTUK MENDORONG DAN MENANAMKAN BUDAYA HEMAT PADA SEKOLAH TAMAN KANAK-KANAK DEUTSCHE INTERNATIONAL SCHULE, BSD CITY, TANGERANG SELATAN. Jurnal ABDIMAS Tri Dharma Manajemen, 1(1), 41-49.

\section{DOKUMENTASI KEGIATAN}
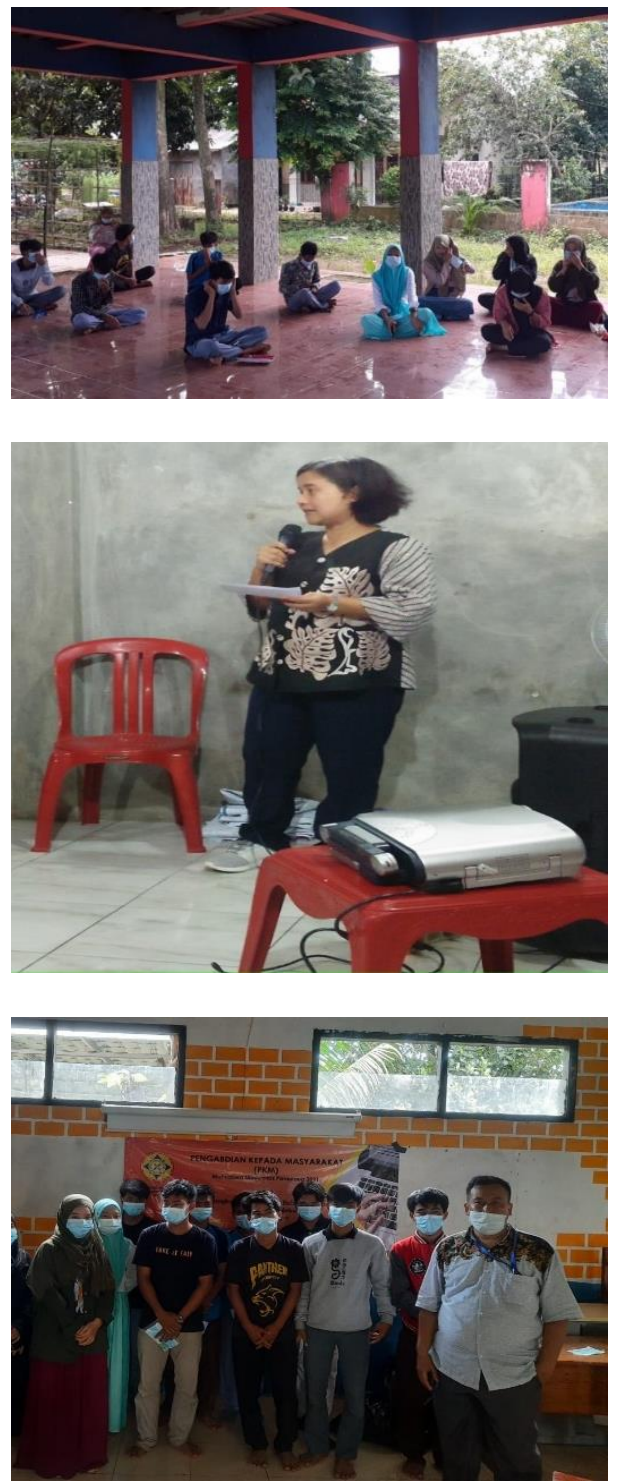